\title{
Pb AND Hg HEAVY METAL TOLERANCE OF SINGLE- AND MIXED- SPECIES BIOFILM (Rhodotorula mucilaginosa AND Escherichia coli)
}

\author{
Anica Buzejić*, Sandra Grujić, Ivana Radojević, Aleksandar Ostojić, \\ Ljiljana Čomić, Sava Vasić
}

\author{
Department of Biology and Ecology, Faculty of Science, University of Kragujevac, \\ Radoja Domanovića 12, 34000 Kragujevac, Republic of Serbia \\ *Corresponding author; E-mail: anicabuzejic@gmail.com
}

(Received March 25, 2016)

\begin{abstract}
The aim of this study was to examine heavy metal tolerance (lead $\left(\mathrm{Pb}^{2+}\right)$ and mercury $\left(\mathrm{Hg}^{2+}\right)$ ) of single- and mixed-species biofilms, formed by yeast Rhodotorula mucilaginosa and bacteria Escherichia coli LM1. Single- and mixed-species biofilms were quantified by crystal violet test and the absorbance was measured using microplate reader $\left(\mathrm{OD}_{570}\right)$. The minimal inhibitory concentration (MIC) and the minimal lethal concentration (MLC) were determined and the results were confirmed by fluorescence microscopy.

The significant difference in lead tolerance was observed between the mixed- and the single-species biofilms. The MIC of lead $\left(\mathrm{Pb}^{2+}\right)$ for the examined biofilms (E. coli LM1, $R$. mucilaginosa and $R$. mucilaginosa / E. coli) was recorded at concentrations of 4000 $\mu \mathrm{g} / \mathrm{ml}, 4000 \mu \mathrm{g} / \mathrm{ml}$ and $16000 \mu \mathrm{g} / \mathrm{ml}$, respectively. The MIC of mercury $\left(\mathrm{Hg}^{2+}\right)$ for the biofilms was noticed at concentrations of $31.25 \mu \mathrm{g} / \mathrm{ml}, 250 \mu \mathrm{g} / \mathrm{ml}$ and $250 \mu \mathrm{g} / \mathrm{ml}$, respectively. Standard antibiotics (amphotericin B and tetracycline) were used as positive control. Results obtained for single-species biofilms were compared in between and with the results obtained for mixed-species biofilm.

The tolerance of the mixed- species biofilm was higher in comparison to the singlespecies biofilms and the results were confirmed by a fluoresecence microscope. The obtained results suggest that the R. mucilaginosa / E. coli biofilm may have a potential to be used in bioremediation of wastewaters contaminated with lead and mercury.
\end{abstract}

Key words: Rhodotorula mucilaginosa, Escherichia coli, biofilm, mixed-species, heavy metals, tolerance.

\section{INTRODUCTION}

The increase of heavy metal concentration in wastewaters is a consequence of industrial development (AHLUWALIA and GOYAL, 2007). Heavy metals present a major problem for the environment and the human health. They are easily accumulated in body cells which leads to an increase of their concentration throughout the food chain (AHLUWALIA and GOYAL, 2007). Typical physical-chemical methods used for the removal of heavy metals from waste waters are inadequate, expensive and produce large quantities of harmful chemical sludge. Bioremediation is considered more suitable and cost-effective method because it involves the use of microorganisms for the purpose of removing heavy metals from wastewater (AHLUWALIA and GOYAL, 2007). 
Microorganisms in natural environments usually form sophisticated communites surrounded by an extracellular matrix called a biofilm (YANG et al., 2011). Biofilm formation can be established by one or several different microbial species, with the latter being the more frequent case. In recent decades a number of studies examined the impact of antimicrobial agents on individual biofilms and it was confirmed that the microorganisms within the biofilm were more tolerant to the effects of antimicrobial agents (HARRISON et al., 2005, 2006; TEITZEL et al., 2003; ELIAS and BANIN, 2011). Numerous studies have examined tolerance of microbial biofilms and planktonic bacterial cultures on the presence of heavy metals (TEITZEL et al., 2003; HARRISON et al., 2005). The results obtained in these studies proved microbial biofilm to be two to 600 times more tolerant to the heavy metal influence.

Since the previous studies have reported a high heavy metal tolerance of yeast (HARRISON et al., 2006) and bacterial biofilms (TEITZEL et al., 2003; HARRISON et al., 2005), the aim of our study was to investigate lead and mercury $\left(\mathrm{Pb}^{2+}\right.$ and $\left.\mathrm{Hg}^{2+}\right)$ tolerance of a mixed biofilm consisting of the Escherichia coli LM1 and the Rhodotorula mucilaginosa strains isolates from the environment.The heavy metal tolerance of different $E$. coli strains (E. coli HM22, E. coli HM21 and E. coli JM109) is already known (HARRISON et al., 2005). However, the previous studies on the heavy metal impact on Rhodotorula species were conducted only on the solitary planktonic cells (SALIES et al., 2000; Li et al., 2008). Because of that, we decided to examine the impact of heavy metals on $R$. mucilaginosa biofilm.

Studies on the mixed-species biofilms are scarce and based on testing the impact of antibiotics (clinical isolates, infective agents) (ADAM et al., 2002; AL-FATTAN and DoUGLAS, 2006). To the authors' knowledge, only one study on the effect of heavy metals on the mixed bacterial biofilm was published (GOLBY et al., 2014). For this reason, the aim of our study was to examine heavy metal tolerance of the mixed-species biofilm (yeast and bacteria) and compare the effect with the single-species biofilms.

\section{MATERIALS AND METHODS}

\section{Microorganisms and growth conditions}

Two species of microorganisms isolated from environment were used in this study the yeast $R$. mucilaginosa and the bacteria $E$. coli LM1.The E. coli LM1 strain is a gift from the Institute for Public Health, Kragujevac, Serbia. The R. mucilaginosa strain was identified by the test for rapid identification of yeast API 20 C AUX (Biomerieux, France). Based on the available literature Tryptic Soy Broth (TSB, Difco) was chosen as the growth medium for the both strains (ADAM et al., 2002).

\section{Biofilms formation}

Tested biofilms (R. mucilaginosa, E. coli LM1 and R. mucilaginosa / E.coli) were formed in polystyrene microtiter 96 well plates (Sarstedt, Germany) according to the method described by ALMEIDA et al. (2011) with certain modifications. The $100 \mu \mathrm{l}$ of suspension $\left(\mathrm{OD}_{520}=0.8\right)$ was added in every well of the plate. To form the mixed $R$. mucilaginosa $/ E$. coli biofilm, an equal amount of suspension was mixed immediately before use.

\section{Preparation of metal solutions}

Metal tolerance of single- and mixed-species biofilms was tested in presence of two metal ions $\mathrm{Pb}^{+} \mathrm{i} \mathrm{Hg}^{2+}$ originating from the $\mathrm{Pb}\left(\mathrm{NO}_{3}\right)_{2}$ and $\mathrm{HgCl}_{2}$ salts (Sigma-Aldrich, St. 
Louis, MO, USA). Stock solutions were filtered using the $0.22 \mathrm{~mm}$ syringe filter in glass vials and stored in the fridge. Work solutions were prepared in TSB medium from stock solutions, no more than $60 \mathrm{~min}$ before use. Since the biofilm of any Rhodotorula species was not tested, range in which heavy metals effect the $R$. mucilaginosa biofilm was unknown. For this reason, a number of different concentrations were tested, and the range was selected, in which the lowest concentration does not lead to a significant response (compared to control) and the highest concentration causes a $100 \%$ test response of the organism. The effect range of lead $(\mathrm{Pb})$ and mercury $(\mathrm{Hg})$ concentrations is shown in Table 1. Standard antibiotics amphotericin $\mathrm{B}$ and tetracycline were used as a control to verify the susceptibility of the $R$. mucilaginosaand E. coli LM1strains isolated from the environment.

Table 1. Range of concentrations $(\mu \mathrm{g} / \mathrm{ml})$ of tested substances

\begin{tabular}{lccccccc}
\hline Column numbers & $\mathbf{1}$ & $\mathbf{2}$ & $\mathbf{3}$ & $\mathbf{4}$ & $\mathbf{5}$ & $\mathbf{6}$ & $\mathbf{7}$ \\
\hline $\mathbf{P b}$ & 2000 & 4000 & 8000 & 16000 & 32000 & 64000 & 128000 \\
\hline $\mathbf{H g}$ & 7.81 & 15.62 & 31.25 & 62.5 & 125 & 250 & 500 \\
\hline Amphotericin B & 7.81 & 15.62 & 31.25 & 62.5 & 125 & 250 & 500 \\
\hline Tetracycline & 7.81 & 15.62 & 31.25 & 62.5 & 125 & 250 & 500 \\
\hline
\end{tabular}

\section{Heavy metal tolerance of tested biofilms}

After the incubation period of $48 \mathrm{~h}$, the tested biofilms (R. mucilaginosa, E.coli LM1 and R. Mucilaginosa / E.coli) were treated with heavy metals and antibiotics. First, the contents of the plate (where the biofilms were formed) were removed. In the each well of the plate $100 \mu \mathrm{l}$ of fresh TSB medium was added and the front wells were treated with $100 \mu 1$ of metal ions and antibiotics in separate wells. Using eight-channel pipette a series of double dilution was made (Table 1). The microtiter plates were placed in an incubator at $26^{\circ} \mathrm{C}$. After $24 \mathrm{~h}, 48 \mathrm{~h}$ and $72 \mathrm{~h}$ quantification was performed using CV (crystal violet) assay according to the method described by ALMEIDA et al. (2011) with certain modifications. Content from the plates was removed after $24 \mathrm{~h}, 48 \mathrm{~h}$ and $72 \mathrm{~h}$, and $50 \mu \mathrm{l}$ of methanol $98 \%$ (vol/vol) was added. After 15 minutes the methanol was removed and the plates were allowed to dry at room temperature. Furthemore, $50 \mu \mathrm{l}$ of crystal violet (CV) was added to each well. After $5 \mathrm{~min}$ the plates were washed three times with sterile distilled water and stored at room temperature to dry. $100 \mu \mathrm{l}$ of $33 \%$ ( $\mathrm{vol} / \mathrm{vol}$ ) glacial acetic acid was added to each well of the plate. Following, the optical density (OD) was measured at $570 \mathrm{~nm}$ using a microplate reader (Rayito, China). All the tests were performed in triplicates and their mean value was calculated. Minimal inhibitory concentration (MIC) and minimal lethal concentration (MLC) were determined. The minimal inhibitory concentration (MIC) is the lowest concentration of an antibiotics or metal ions that will inhibit the visible growth of biofilm populations. The minimal lethal concentration (MLC) is defined as the concentration of an antimicrobial agent that kills $95-100 \%$ of biofilm populations (HARRISON et al., 2005).

\section{Fluorescence Microscopy}

Fluorescence microscopy was used to examine the influence of heavy metals on tested biofilms according to the method described by KRONWALL and MYHRE (1977) with certain 
modifications. Tested biofilms were observed on the Olympus BX51 fluorescence microscope (Olympus, Shinjuku, Tokyo, Japan) and analyzed using Cytovision 3.1 software package (Applied Imaging Corporation, Santa Clara, California, USA).

The content of the microtiter plate was removed. In each well of a microtiter plate 50 $\mu l$ of methanol was added in order to perform fixation of the biofilm to the walls of the plate. Thus prepared microtiter plate was incubated at room temperature to vapors of the methanol. After incubation, $50 \mu \mathrm{l}$ of acridine orange stain $(5 \mathrm{mg} / \mathrm{ml})$ was added in microtiter plate. After 2 min the microtiter plate was washed with sterile distilled water. Tested biofilms were then observed using a fluorescent microscope.

\section{RESULTS}

\section{Biofilm formation after $24 \mathrm{~h}, 48 \mathrm{~h}$ and $72 \mathrm{~h}$}

In this study we tested ability $R$. mucilaginosa and E. coli LM1 to form single- and mixed-species biofilm in 96-well microtiter plates. The formation of single- and mixedspecies biofilm was tested using crystal violet. The results are shown in Figure 1.

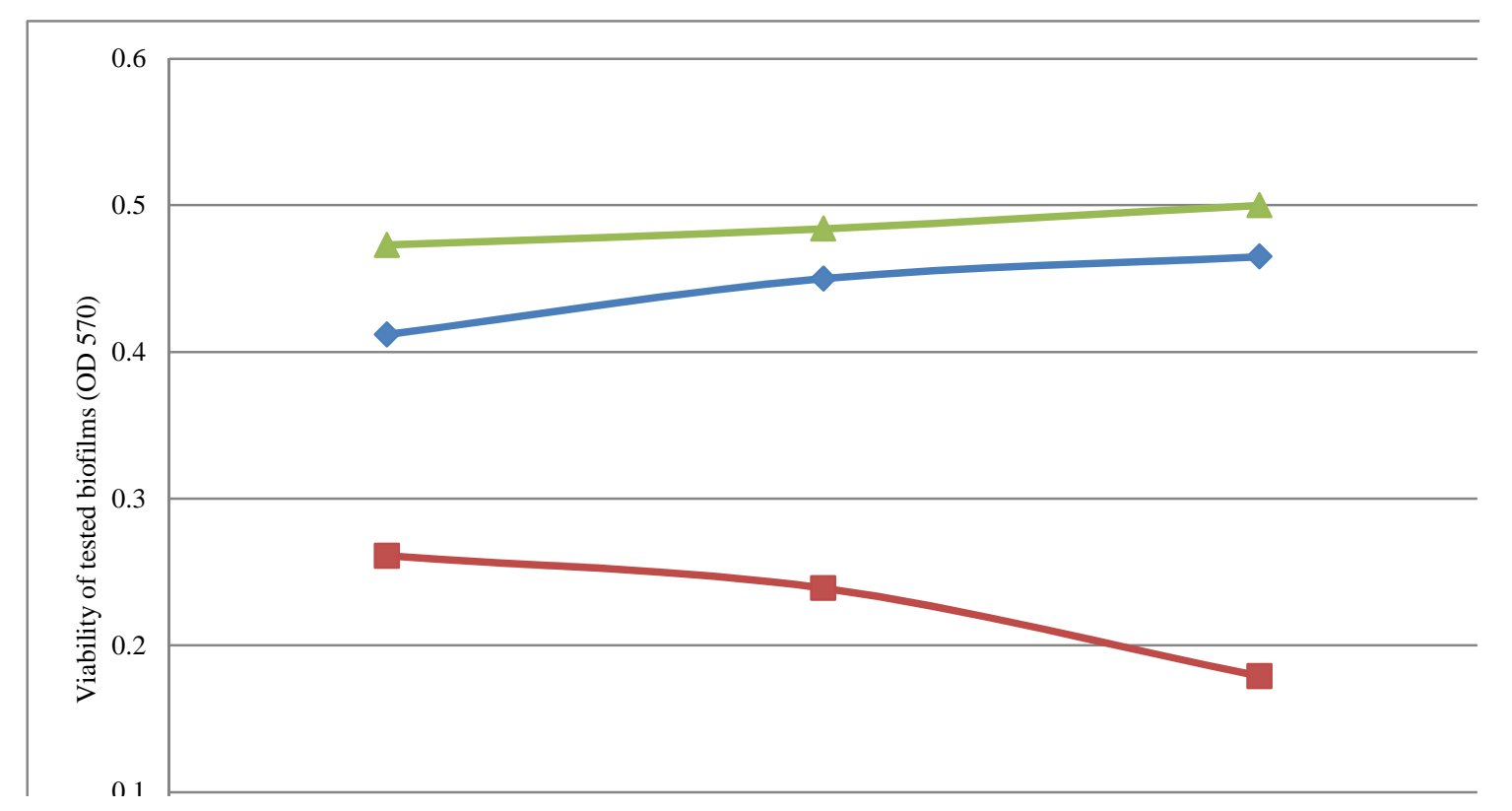

Figure 1. Growth control of $R$. mucilaginosa, E. coli LM1

and $R$. mucilaginosa / E. coli biofilms during $24 \mathrm{~h}, 48 \mathrm{~h}$ and $72 \mathrm{~h}$.

Figure 1. shows growth control of the $R$. mucilaginosa, E.coli LM1 and $R$. mucilaginosa / E c coli biofilms formed in 96 well microtiter plate during $24 \mathrm{~h}$, $48 \mathrm{~h}$ and $72 \mathrm{~h}$ period. The growth control of the mixed-species biofilm was better compared to the singlespecies biofilms.

\section{Heavy metal tolerance of tested biofilms}

The MIC and the MLC of single- and mixed-species biofilm were determined. MIC for single-species biofilm E. coli LM1 was determined after 24h and MLC after 48h. MIC for single-species biofilm $R$. mucilaginosa and mixed-species biofilm were determined after $48 \mathrm{~h}$ and MLC after $72 \mathrm{~h}$. The results were shown in Table 2. 
The obtained results were shown a significant difference in lead tolerance between the mixed- and the single-species biofilms. There was no difference in mercury tolerance between the mixed-species biofilm and the $R$. mucilaginosa biofilm.

Table 2. Heavy metal tolerance of single- and mixed-species biofilm

\begin{tabular}{|c|c|c|c|c|c|c|}
\hline \multirow{3}{*}{ Tested substance } & \multicolumn{4}{|c|}{ Single biofilm } & \multirow{2}{*}{\multicolumn{2}{|c|}{$\begin{array}{c}\text { Mixed biofilm } \\
\text { Rhodotorula/E. coli }\end{array}$}} \\
\hline & \multicolumn{2}{|c|}{ Rhodotorula sp. } & \multicolumn{2}{|c|}{ E. coli LM1 } & & \\
\hline & MIC* & MLC*** & MIC & MLC & MIC & MLC \\
\hline $\mathbf{P b}$ & 4000 & 64000 & 4000 & 16000 & 16000 & 32000 \\
\hline Hg & 250 & 500 & 31.25 & 62.5 & 250 & 500 \\
\hline Amphotericin B & 7.81 & 62.5 & 7.81 & 31.25 & 250 & 500 \\
\hline Tetracycline & 62.5 & 125 & 15.25 & 62.5 & 500 & 500 \\
\hline
\end{tabular}

\section{Fluorescence Microscopy}

The impact of heavy metals and antibiotics amphotericin B (pictures on the figures marked with A) and tetracycline (marked with a $\mathrm{T}$ ) on the test biofilms was monitored for $24 \mathrm{~h}, 48 \mathrm{~h}$ and $72 \mathrm{~h}$. The results are shown in Figures 2-10. Numbers from 1 to 7 are marking a range of concentrations (Table 1).

Considering that the impact of heavy metals was monitored during the various incubation periods, it was noticed that the heavy metal tolerance of the biofilms decreased with time.

\section{DISCUSSION}

\section{Heavy metal tolerance of tested biofilms}

Heavy metal tolerance of single- and mixed-species biofilm were tested in our study. The MIC and MLC for tested biofilms were determined. The MLC of $\mathrm{Hg}$ and $\mathrm{Pb}$ for the $R$. mucilaginosa biofilm was observed at concentrations of $500 \mu \mathrm{g} / \mathrm{ml}$ and $64000 \mu \mathrm{g} / \mathrm{ml}$, respectively. HARRISON et al. (2006) reported that a Candida tropicalis biofilm was more tolerant on the presence of heavy metals compared to the planktonic cells of this species. In their study the $\mathrm{MLC}_{100}$ for the C. tropicalisbiofilm in the presence of $\mathrm{Hg}$ and $\mathrm{Pb}$ was observed at concentrations of $515 \mu \mathrm{g} / \mathrm{ml}(1.9 \mathrm{mM})$ and $>20728$ biofilm $\mu \mathrm{g} / \mathrm{ml}(>77 \mathrm{mM})$, respectively. The results of our study were in accordance with the MLC results of previous study, especially for the $\mathrm{Hg}$ test. The obtained MIC results for $\mathrm{Pb}$ were partially in accordance with the mentioned study, since the authors did not determine the MLC of $\mathrm{Pb}$.

HARRISON et al. (2005) examined the effect of chromium $\left(\mathrm{CrO}^{2-}{ }_{4}\right)$, arsenate $\left(\mathrm{AsO}^{3-}{ }_{4}\right)$, arsenite $\left(\mathrm{AsO}_{2}^{-}\right)$, selenite $\left(\mathrm{SeO}_{3}^{2-}\right)$, telluride $\left(\mathrm{TeO}^{2-}{ }_{4}\right)$ and tellurite $\left(\mathrm{TeO}^{2-}{ }_{3}\right)$ on the biofilm and planktonic cells of E. coli JM109. The E. coli JM109 biofilm exhibited high tolerance to the presence of tested metal anions which was in accordance with our results obtained for the $E$. coli LM1 biofilm (Table 2). 


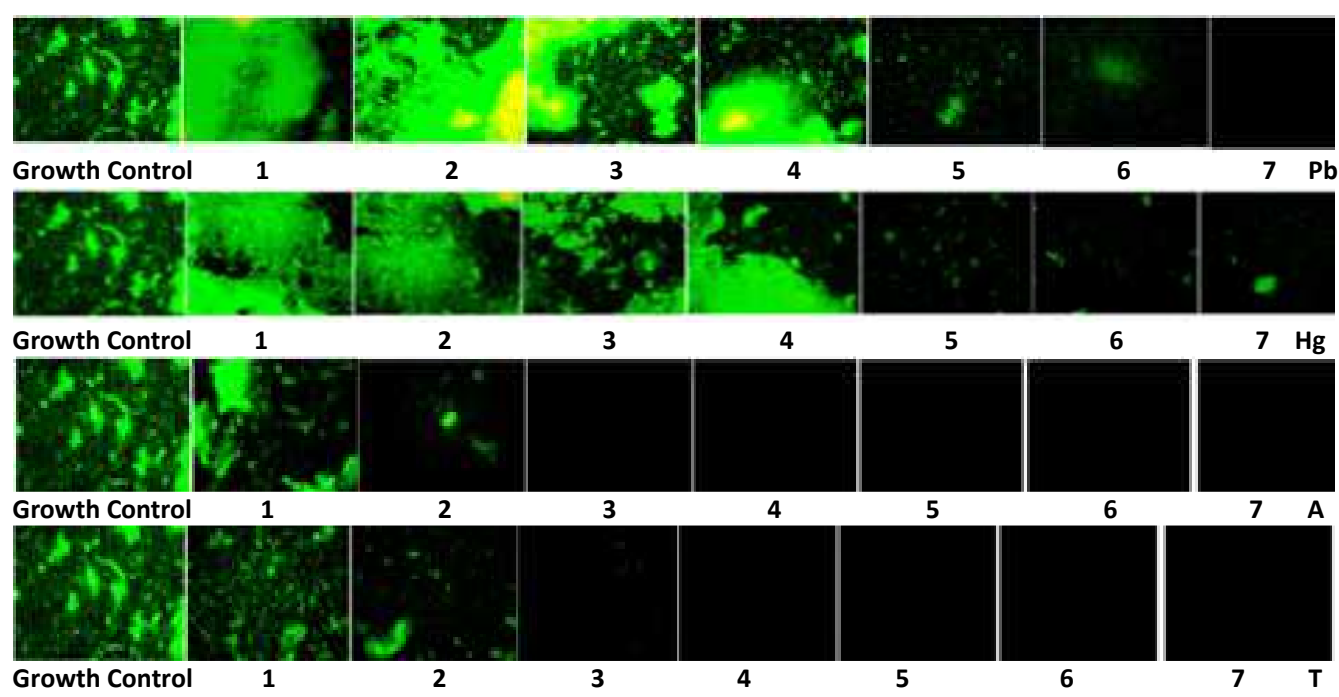

Figure 2. Effects of tested substances on the E. coli LM1 biofilm after 24h.

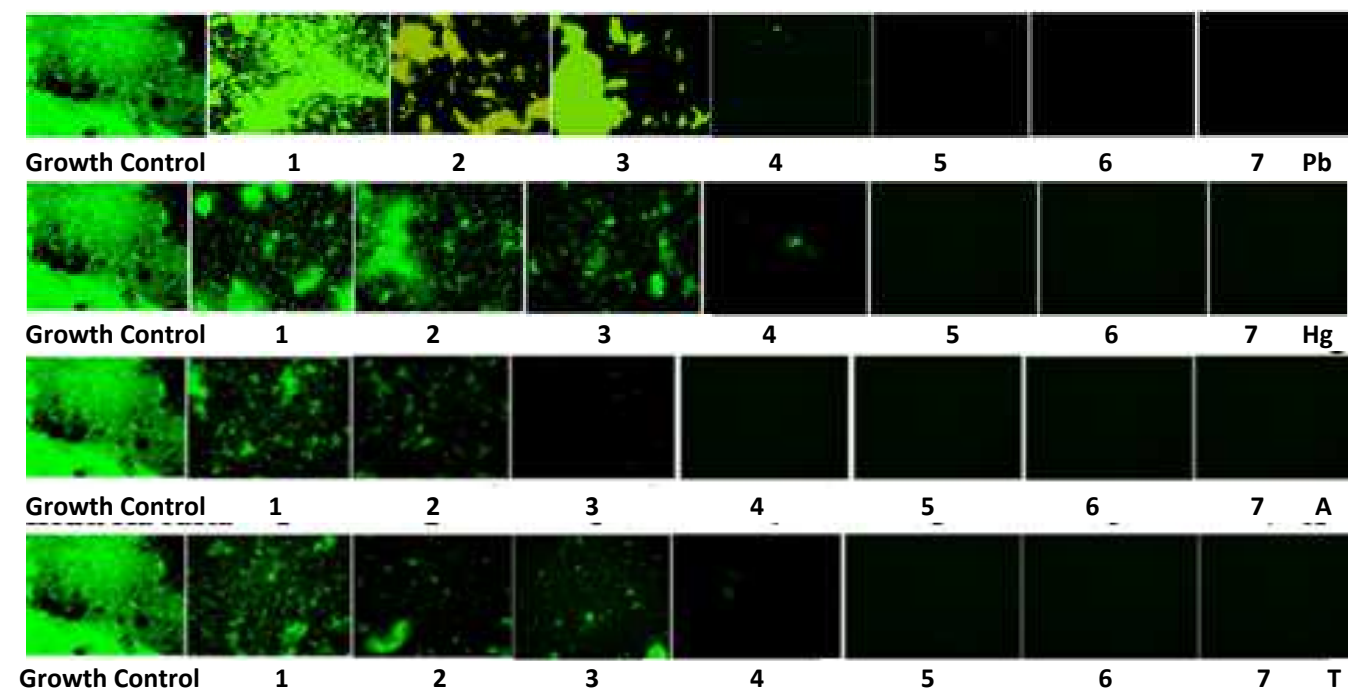

Figure 3. Effects of tested substances on the E. coli LM1 biofilm after 48 h.

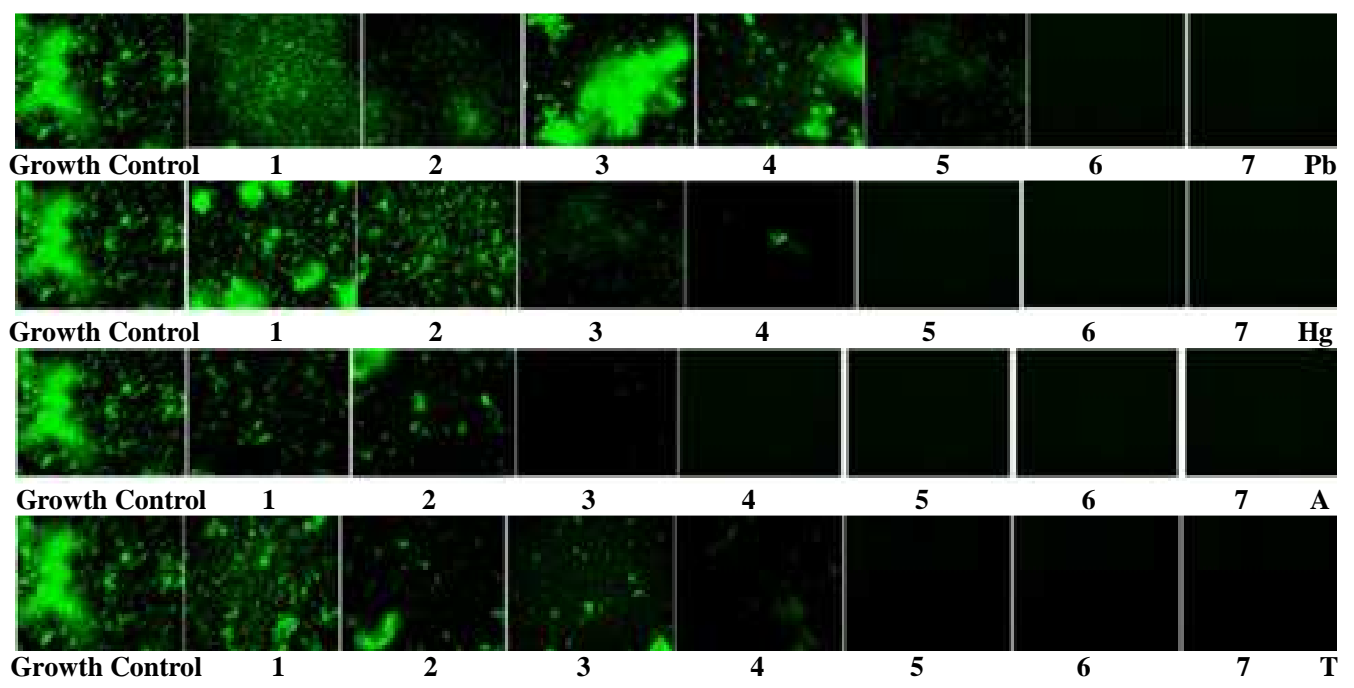

Figure 4. Effects of tested substances on the E. coli LM1 biofilm after 72h. 


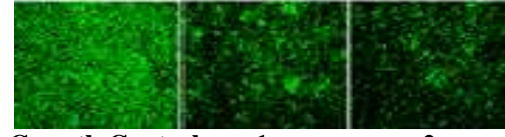

Growth Control

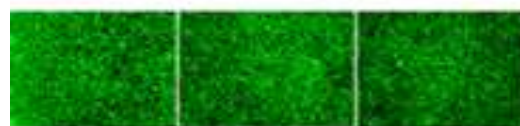

Growth Control

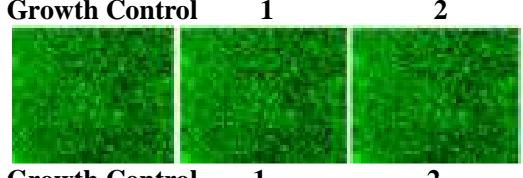

Growth Control 1

2

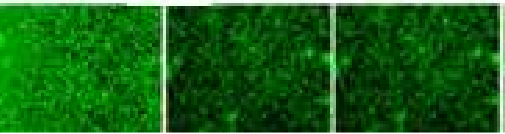

Growth Control

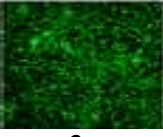

3

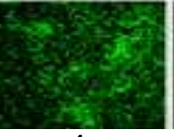

4

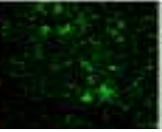

5
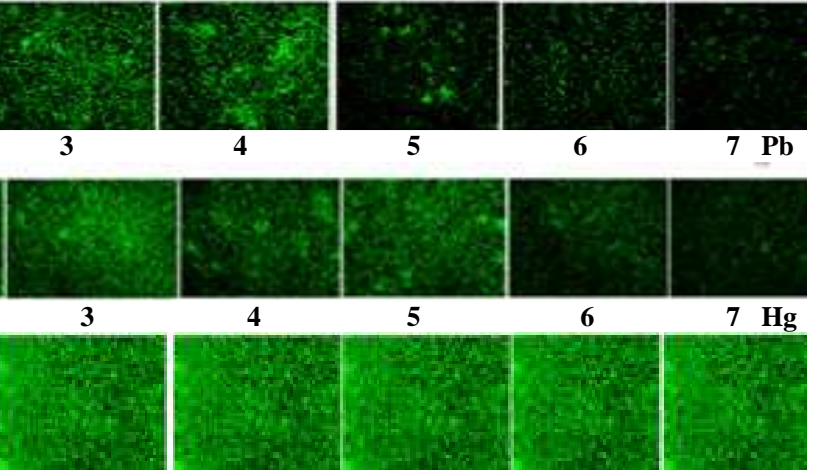

3
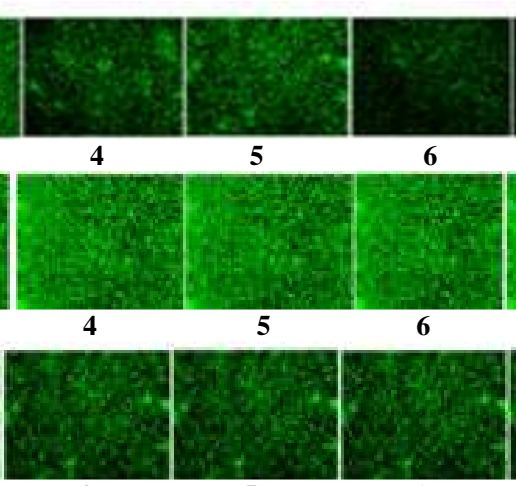

6

7 A

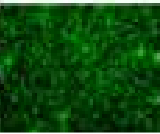

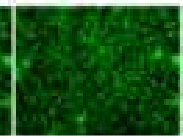

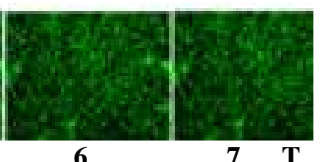

Figure 5. Effects of tested substances on the R. mucilaginosa biofilm after $24 \mathrm{~h}$.
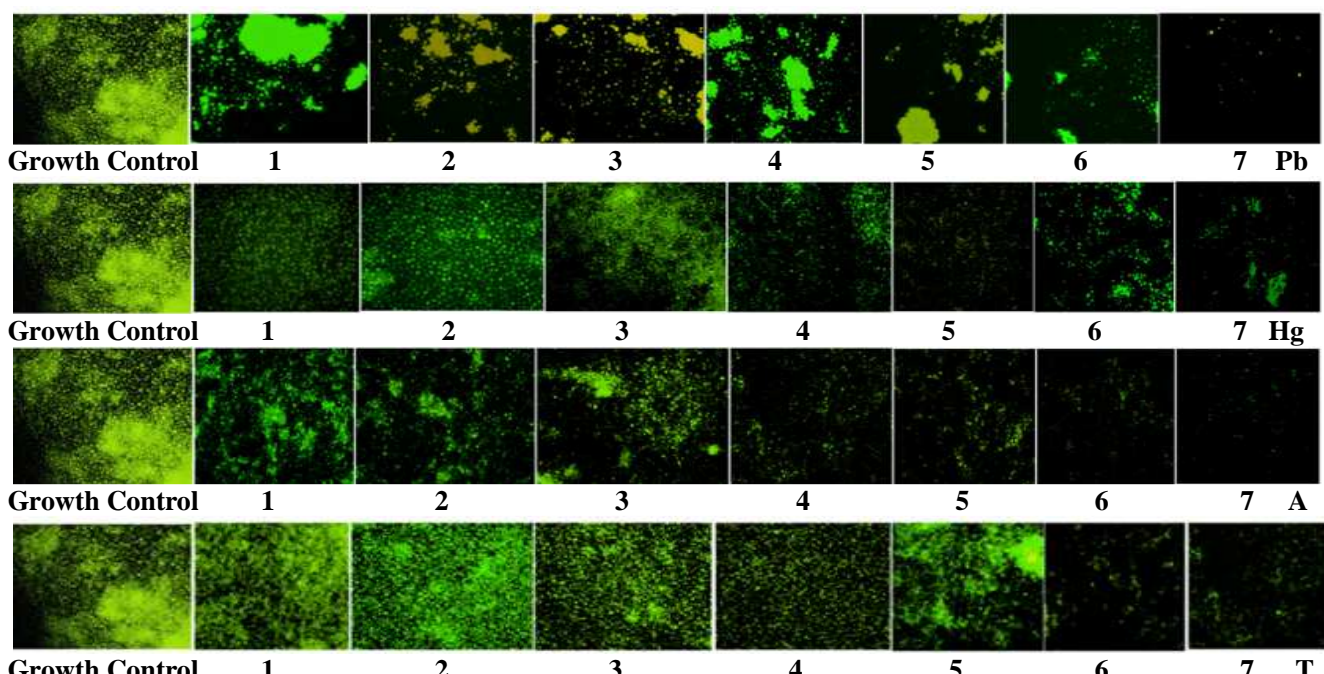

Growth Control

4

$\mathbf{T}$

Figure 6. Effects of tested substances on the R. mucilaginosa biofilm after $48 \mathrm{~h}$.

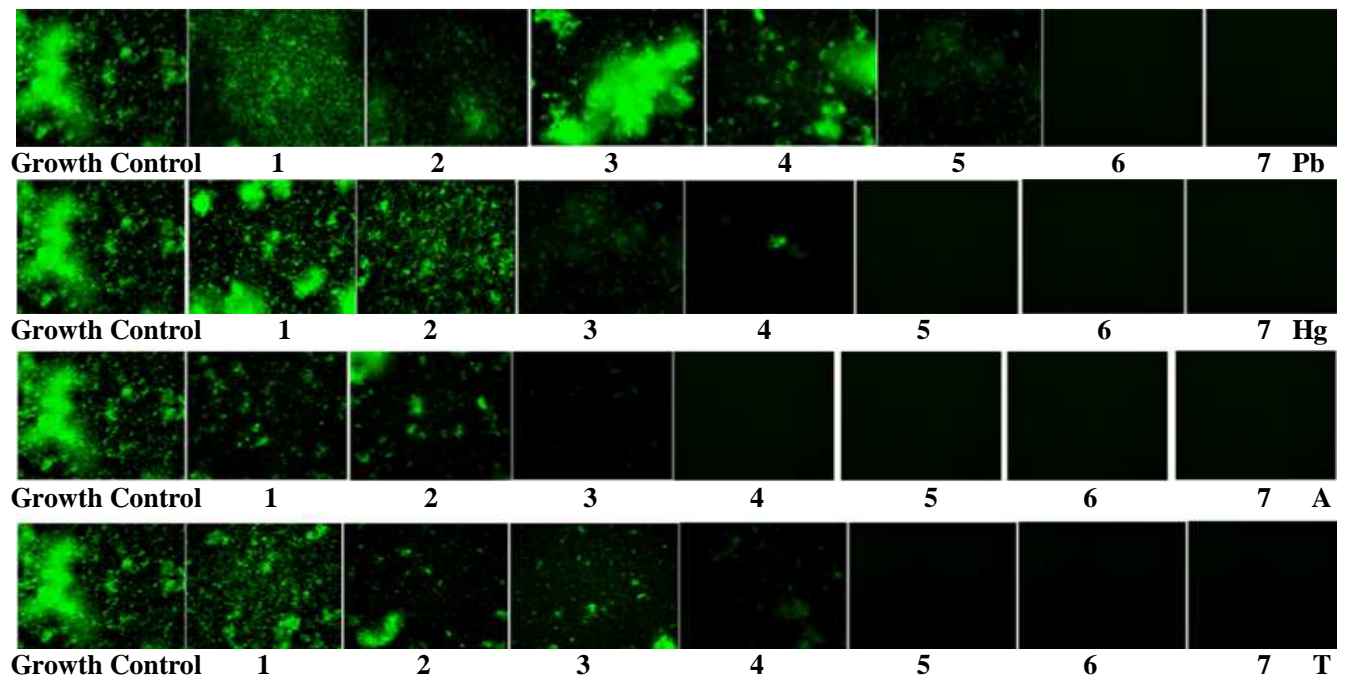

Figure 7. Effects of tested substances on the R.mucilaginosa biofilm after 72 . 

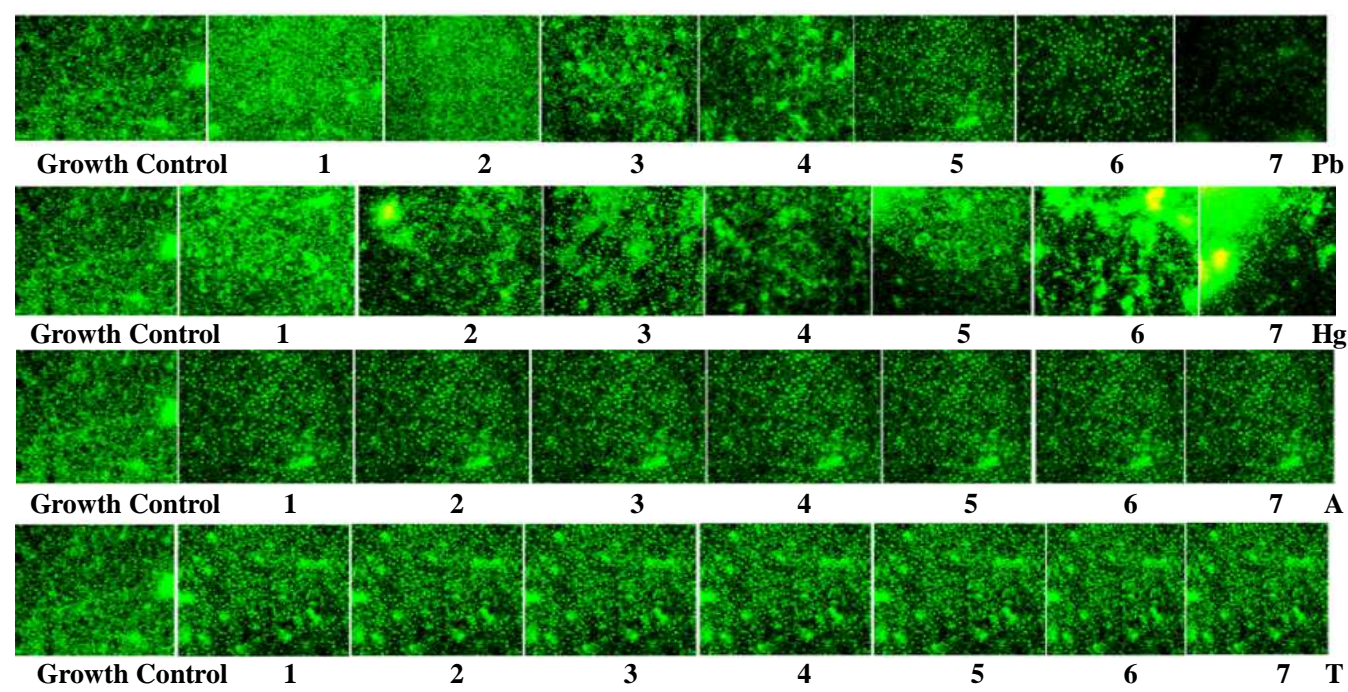

Figure 8. Effects of tested substances on the mixed-species biofilm after $24 \mathrm{~h}$.

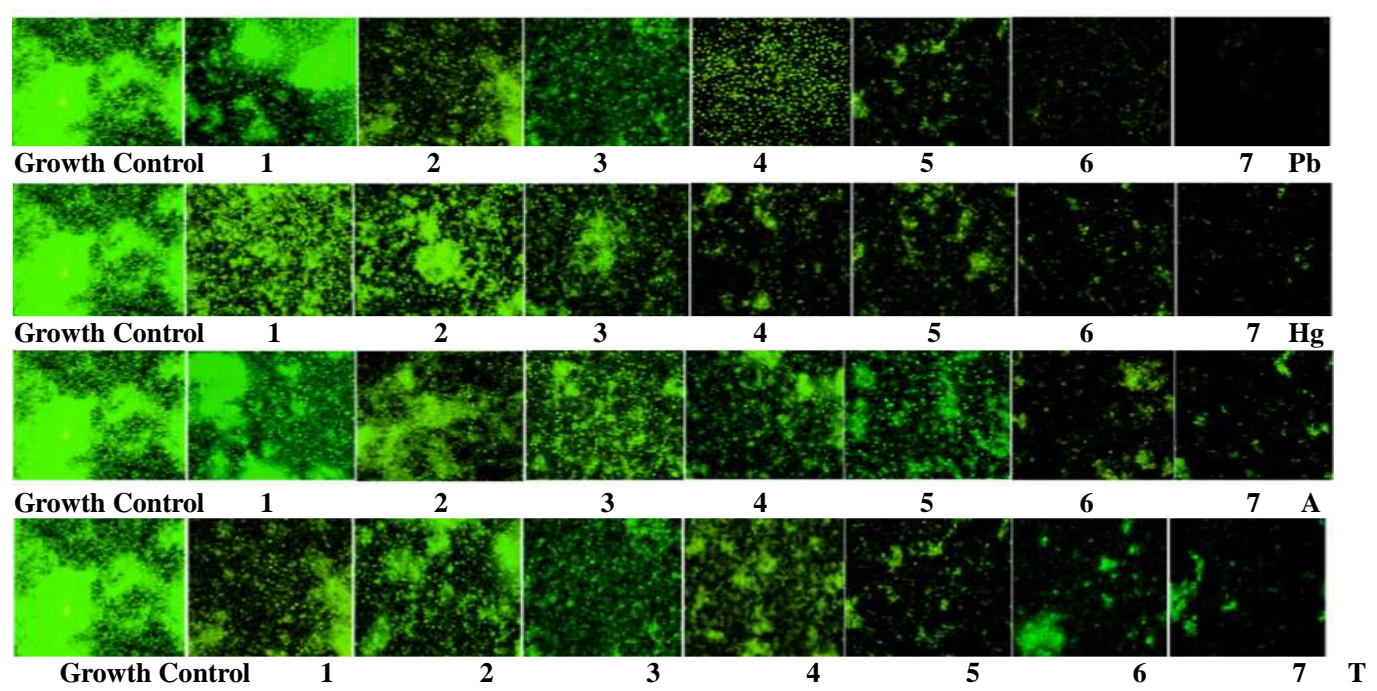

Figure 9. Effects of tested substances on the mixed-species biofilm after $48 \mathrm{~h}$.

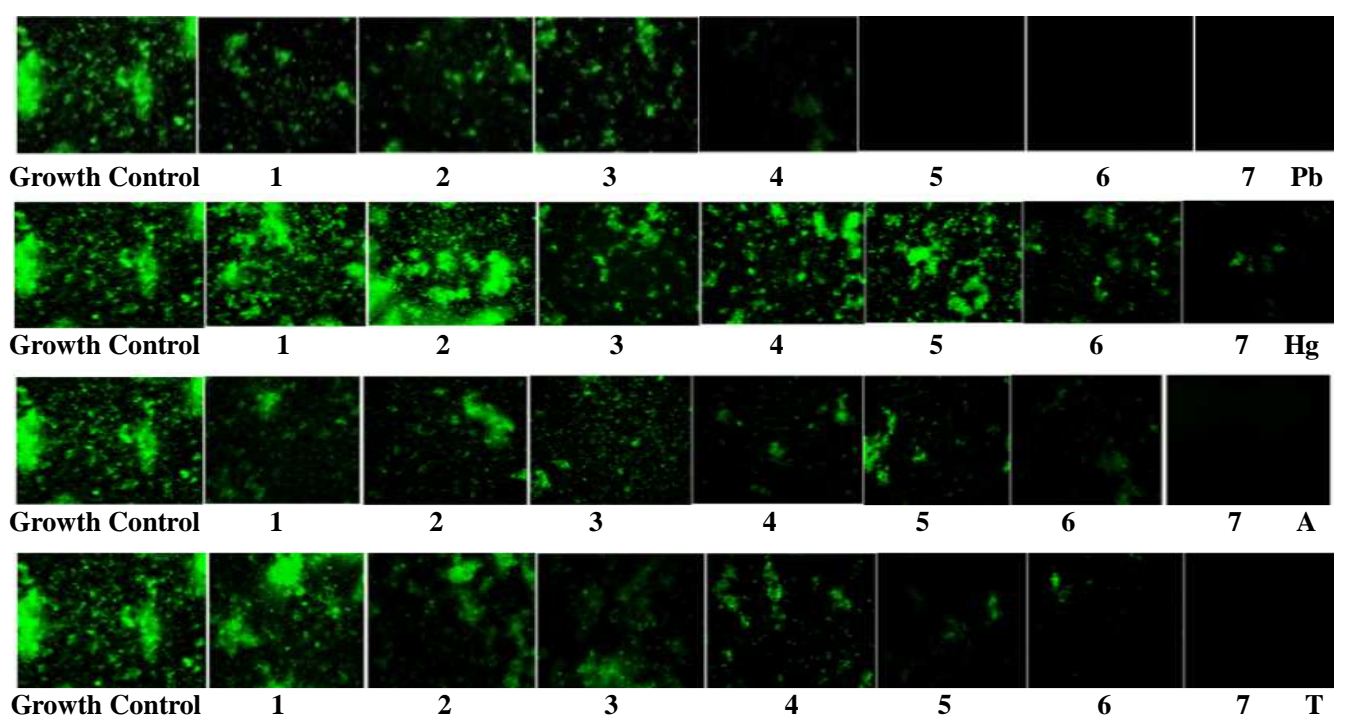

Figure 10. Effects of tested substances on the mixed-species biofilm after 72h. 
The mixed-species biofilm showed to be more tolerant to antimicrobial treatment in comparison with single-species biofilms (LERICHE et al., 2003). The results of our study showed that heavy metal tolerance of mixed-species biofilm was higher compared to the single-species biofilms, which is in accordance with the results reported in mentioned study. The largest difference in lead tolerance was observed between the mixed and the single species biofilms. The MIC of $\mathrm{Pb}^{2+}$ for the examined biofilms (E. coli LM1, R. mucilaginosa and R. mucilaginosa / E. coli) was recorded at concentrations of $4000 \mu \mathrm{g} / \mathrm{ml}, 4000 \mu \mathrm{g} / \mathrm{ml}$ and $16000 \mu \mathrm{g} / \mathrm{ml}$, respectively. The MIC of $\mathrm{Hg}^{2+}$ for the biofilms was noticed at concentrations of $31.25 \mu \mathrm{g} / \mathrm{ml}, 250 \mu \mathrm{g} / \mathrm{ml}, 250 \mu \mathrm{g} / \mathrm{ml}$, respectively.

Heavy metal tolerance of mixed-species biofilms was also examined by GoLBY et al., (2014). The biofilm used in this study was isolated from the sludge tailings in North Alberta (Canada) and its tolerance on the presence of metal ions including $\mathrm{Cu}, \mathrm{Ag}, \mathrm{Pb}, \mathrm{Ni}, \mathrm{Zn}, \mathrm{V}, \mathrm{Cr}$, and $\mathrm{Sr}$ was tested. The obtained results showed that the mixed bacterial biofilm was extremely resistant to the applied metal ions. The reported tolerance values were as follows; over 20 $\mathrm{mg} / \mathrm{l}$ for $\mathrm{Pb}, 16 \mathrm{mg} / \mathrm{l}$ for $\mathrm{Zn}, 1000 \mathrm{mg} / \mathrm{l}$ for $\mathrm{Sr}$, and $3.2 \mathrm{mg} / \mathrm{l}$ for Ni. In our study, the MIC of Pb for the mixed-species biofilm was observed at $16000 \mu \mathrm{g} / \mathrm{ml}$. In the study of GOLBY et al. (2014) mixed bacterial biofilm showed resistance to the effect of $\mathrm{Pb}$ in concentration over 20 $\mathrm{mg} / \mathrm{l}$, which is partially in accordance with the results of our study.

Furthermore, ADAM et al. (2002) examined the effect of antibiotics on mixed-species biofilm consisting of yeast Candida albicansand bacteria Staphylococcus epidermidis. Both species are pathogenic and infection causers. In this study, results showed that bacteria and yeast ensure the survival of each other when forming a mixed biofilm. The results of ADAM et al. (2002) study were in accordance with the results of our study where the mixed biofilm was about 65 times more tolerant to the effect of antibiotics compared to single biofilms (Table 2).

\section{CONCLUSION}

Heavy metals influence on single- and mixed-species biofilms composed by yeast $R$. mucilaginosa and bacteria E.coli LM1 strains, isolated from the environment was examinated in this study. The tolerance of the mixed-species biofilm was higher in comparison to the single-species biofilms. The results suggest that mixed-species biofilms could be more effective in the process of bioremediation than single-species biofilms, which opens the possibility for future tests of $R$. mucilaginosa / E. coli biofilm in the remediation of contaminated water.

\section{Acknowledgment}

This study was supported by the Serbian Ministry of Education, Science, and Technological Development (Project No. III 41010).

\section{References:}

[1] Adam, B., Baillie, G.S., Douglas, L.J. (2002): Mixed species biofilms of Candida albicans and Staphylococcus epidermidis. Journal of Medical Microbiology 51: 344349. 
[2] Ahluwalia, S.S., Goyal, D. (2007): Microbial and plant derived biomass for removal of heavy metals from wastewater. Bioresours Technology 8: 2243-57.

[3] Al-Fattani, M.A., Douglas, L.J. (2006): Biofilm matrix of Candida albicans and Candida tropicalis: chemical composition and role in drug resistance. Journal of Medical Microbiology 55: 999-1008.

[4] Almeida, C., Azevedo, N.F., Santos, S., Keevil, C.W., Vieira, M.J. (2011): Discriminating multi-species populations in biofilms with peptide nucleic acid fluorescence in situ hybridization. PLoS One 6: e14786.

[5] Elias, S., BANIN, E. (2012): Multi-species biofilms: living with friendly neighbors. FEMS Microbiology Reviews 36: 990-1004.

[6] Golby, S., Ceri, H., Marques, L.L., Turner, R.J. (2014): Mixed-Species Biofilms Cultured from an Oil Sand Tailings Pond can Biomineralize Metals. Microbial ecology 68: $70-80$.

[7] Harrison, J.J., Ceri, H., Roper, N.J., Badry, E.A., Sproule, K.M. and Turner, R.J. (2005): Persister cells mediate tolerance to metal oxyanions in Escherichia coli. Microbiology society 151: 3181-3195.

[8] Harrison, J.J., Rabiei, M., Turner, R.J., Badry, E.A., Sproule, K.M. and Ceri, H. (2006): Metal resistance in Candida biofilms. FEMS microbiology ecology 55: 479-491.

[9] Kronvall, G., Myhre, E.B. (1977): Differential staining of bacteria in clinical specimens using acridine orange buffered at low $\mathrm{pH}$. Acta Pathologica et Microbiologica Scandinavica - Section B. Microbiology 85: 249-254.

[10] LERICHE, V., BRIANDET, R., CARPENTIER, B. (2003): Ecology of mixed biofilms subjected daily to a chlorinated alkaline solution: spatial distribution of bacterial species suggests a protective effect of one species to another. Environmental Microbiology 5: 64-71.

[11] LI, Z., YUAN, H.L., HU, X.D. (2008): Cadmium-resistance in growing Rhodotorula sp. Y11. Bioresource technology 99: 1339-1344.

[12] Salinas, E., de Orellano, M.E., Rezza, I., Martinez, L., Marchesvky, E., De TOSETTI, M.S. (2000): Removal of cadmium and lead from dilute aqueous solutions by Rhodotorula rubra. Bioresource Technology 72: 107-112.

[13] Teitzel, G.M., PARSeK, M.R. (2003): Heavy metal resistance of biofilm and planktonic Pseudomonas aeruginosa. Applied and environmental microbiology 69: 2313-2320.

[14] Yang, L., Hoiby, N., Molin, S. and Song, Z. (2011): Current understanding of multispecies biofilms. International Journal of Oral Science IJOS 3: 74-81. 